\title{
Dicle Üniversitesi Mühendislik Fakültesinin Rüzgâr ve Sıcaklık Etkilerinin Nümerik Olarak İncelenmesi
}

\author{
Ömer Faruk Can \\ Dicle Üniversitesi, Mühendislik Fakültesi, Makine Mühendisliği Bölümü, Diyarbakır, Türkiye \\ faruk.can@dicle.edu.tr (D)
}

Makale gönderme tarihi:03.05.2021, Makale kabul tarihi: 10.09.2021

\begin{abstract}
$\ddot{\mathbf{O} z}$
$\mathrm{Bu}$ çalışmada Dicle Üniversitesi Mühendislik Fakültesinin rüzgâr ve sıcaklık etkileri nümerik olarak incelenmiştir. Çalışma 4 durumda ele alınmıştır. Sirasıyla rüzgârın güneydoğu (ön kısım), kuzeybatı (arka kısım), kuzeydoğu (sağ kısım) ve güney batı (sol kısım)'dan esmesi durumunda bina üzerindeki rüzgâr ve akış özellikleri incelenmiştir. Çalışma hesaplamalı akışkanlar dinamiği uygulamalarında sıklıkla kullanılan ANSYS CFX yazılım programı yardımıyla gerçekleştirilmiştir. Giriş kısmında rüzgâr hızı $40 \mathrm{~m} / \mathrm{s}$ olarak alınmıştır. Giriş rüzgâr sıcaklığı $35^{\circ} \mathrm{C}$ olarak verilmiştir. Rüzgâr yönlerinin tespit edilmesi için Google haritalar uygulaması yardımıyla binanın uydu görüntüleri alınmıştır. Bina yüzey sıcaklığ $125^{\circ} \mathrm{C}$ olarak belirlemiştir. Bina boyutları için gerçek ölçüler kullanılmıştır. Çalışma sonunda 4 durum için hız konturları ve akım çizgileri elde edilmiştir. Ayrıca binanın orta noktasından geçen bir çizgi boyunca ortalama hız ve sıcaklık grafikleri verilmiştir.
\end{abstract}

Anahtar Kelimeler: Nümerik analiz, rüzgâr direnci, rüzgâr etkileri, hesaplamalı akışkanlar dinamiği, akım çizgileri

\section{Numerical Investigation of Wind and Temperature Effects of Dicle University Faculty of Engineering}

\begin{abstract}
In this study, wind and temperature effects of Dicle University Engineering Faculty were investigated numerically. The study was handled in 4 cases. In case the wind blows, respectively, from southeast (front part), northwest (rear part), northeast (right part) and south west (left part) the wind and flow characteristics on the building were examined. The study was carried out with the used ANSYS CFX software program, which is frequently used in computational fluid dynamics applications. In the entrance, wind speed has been taken as $40 \mathrm{~m} / \mathrm{s}$. Inlet wind temperature is given as $35^{\circ} \mathrm{C}$. In order to determine the wind directions, satellite images of the building were taken with the used of google maps application. Building surface temperature was determined as $25^{\circ} \mathrm{C}$. Actual dimensions are used for building dimensions. At the end of the study, velocity contours and streamlines were obtained for 4 cases. In addition, were given graphs of average velocity and temperature along a line passing through the middle of the building.
\end{abstract}

Keywords: Numerical analysis, wind resistance, wind effects, computational fluid dynamics, streamlines

\section{GíRIŞ}

Rüzgâr direnci ve etkileri tüm yapılarda karşımıza çıkmaktadır. Binaların yüksek rüzgâr hızına maruz kalması durumunda özellikle yüksek binalarda gürültü ve titreşime neden olabilmektedir. Rüzgâr hızının çok yüksek değerlere ulaştı̆̆ kasırga gibi doğal afetlerde gürültü ve titreşimin yanı sıra can ve mal kaybı da olabilmektedir. Özellikle köşe noktalarda hız artışı girdap artışına da neden olmaktadır. $\mathrm{Bu}$ durum yüzeylerde yüksek sürtünmeyle birlikte bina yüzeylerinin siklıkla aşınmasına hatta bazı parçaların bina yüzeylerinden ayrılmasına neden olmaktadır. Cam gibi yüzeyler kırilabilmekte ve yaralanmalara neden olabilmektedir. Yeni binalarda bu durumun önüne geçmek için; bir sahil kenarında dalga kırıcıların yerleştirilmesi gibi binada pencere olan yüzeylerin ön kısımlarına rüzgâr etkisini azaltıcı dikey yâda yatay elemanlar koyulmaktadır. Hemant vd., 2019 üstten görünüşü kare olan yüksek bir binanın rüzgâra maruziyetini sayısal olarak gerçekleştirmişlerdir. Rüzgâr etkilerini iki farklı türbülans model kullanarak incelemişlerdir. Çalışma sonunda bina 
üzerindeki hı konturlerinin değişimini incelemişlerdir. Jae vd., 2020 rüzgârın yıkıcı etkileri üzerine bir araştırma yapmışlardır. Çalışma sonunda rüzgârın tahrip ettiği yapıları ele almışlardır. Jinsoo vd., 2017 tek taraflı havalandırma sistemine sahip bir yapıda iç ve dış kısım arasında pozitif ve negatif sıcaklık farklarını ele almışlardır. Ayrıca yapının tek taraflı hava alan kısmında içeri giren rüzgârın

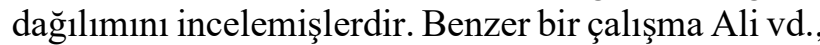
2019 tarafından gerçekleştirilmiştir. Bina üzerindeki hız profillerini farklı türbülans modelleri kullanarak incelemişlerdir. Gölbaşı vd., 2017, dört farklı bina modelleri etrafındaki akış alanlarını; ortalama hız ve türbülans hız profillerinin ölçülmesi Parçacık Görüntülemeli Hız Ölçüm tekniği (PIV) yöntemi kullanarak deneysel olarak incelenmişlerdir. Gölbaşı vd., 2017, iki bina arasındaki akış özelliklerini deneysel ve sayısal olarak incelemişlerdir. Çalışmada çatı katının etkilerini incelemişlerdir. Gölbaşı vd., 2017, bina yüksekliği değişiminin akış yapıları üzerindeki etkilerini incelemişlerdir. Bina modelleri olarak, $30^{\circ}$ eğime sahip çat1l $5 \times 5 \times 5 \mathrm{~cm}$ ve $5 \times 10 \times 5 \mathrm{~cm}$ boyutlarındaki yapıları fluent 12.0 programı kullanarak incelemişlerdir. Gölbaşı vd. 2018, çalışmalarında $5 \times 5 \times 5 \mathrm{~cm}$ boyutlarında çatılı ve çatısız iki bina modeli etrafındaki akış özelliklerini deneysel ve sayısal olarak incelemiş olup, çatılı bina arkasındaki girdapların uzunluklarının çatılı binaya göre \% 7,5 oranında arttı̆̆ını belirlemişlerdir.

Binalarda rüzgâr etkilerinin yanı sira yalıtım özellikleri de önem arz etmektedir. Erdem ve Volkan., 2017 Tunceli, Hakkâri ve Kars illerinin optimum 1s1 yalıtım kalınlığının Hesaplanması ile ilgili bir çalışma gerçekleştirmişlerdir. Xiao vd., 2019 Çin'in Dali şehrindeki 42 katlı iki binanın hasar olasılığ 1 üzerine bir çalıșma yapmıșlardır. Çalıșmada rüzgârın geliş açılarının bina üzerindeki etkilerini ele almışlardır.

Hava perdeleri binalardaki rüzgâr etkilerini azaltıcı etkiye sahiptir. Dolayısıyla binanın enerji ekonomisi açısından olumlu sonuçlar sağlamaktadır. Senwen vd., 2019 binalardaki hava perdeleri üzerine bir çalışma gerçekleştirmişlerdir. Çalışmayı bir rüzgâr tüneli test bölgesi kullanarak gerçekleştirmişlerdir. Ayrıca nümerik model oluşturarak sonuçları karşılaştırmışlardır. Bendine ve Alper., 2020 bir köprünün enerji tasarrufu bakımindan sayisal modellemesini gerçekleştirmişlerdir. Filmon vd., 2017 Binalardaki rüzgâr etkileri üzerine bir çalışma gerçekleştirmişlerdir. Andrew vd. 2020, binalardaki rüzgâr ve deprem etkilerini incelemişlerdir. Leonidas ve Marialena., 2019 binaların yükseklik ve alan oranları ve rüzgâr konforu üzerine bir çalışma gerçekleştirmişlerdir. Cheng vd., 2020 binalarda rüzgâr basınç katsayılarını incelemişlerdir. Timothy vd., 1998 rüzgâr-kuvvet dirençleri üzerine bir çalışma gerçekleştirmişlerdir. Li vd., 2019 şehirlerdeki binaların rüzgâr etkileri üzerine bir çalışma gerçekleştirmişlerdir.

$\mathrm{Bu}$ çalışmada amaç, Dicle Üniversitesi Mühendislik Fakültesinin dış duvarlarının rüzgâr ve sıcaklık etkileri bakımından incelenmesidir. Çalışma nümerik olarak 4 durum için gerçekleştirilmiştir. Sırasıyla rüzgârın güneydoğu (ön kısım), kuzeybatı (arka kısım), kuzeydoğu (sağ kısım) ve güney batı (sol kısım)'dan esmesi durumunda bina üzerindeki rüzgâr ve akış özellikleri incelenmiştir.

\section{MATERYAL VE METOT}

Çalışma hesaplamalı akışkanlar dinamiği uygulamalarında sıklıkla kullanılan ANSYS CFX 18.2 yazilım programı kullanılarak gerçekleştirilmiștir. Çalıșma kapsamında Dicle Üniversitesi Mühendislik Fakültesi binası rüzgâr etkileri yönünden incelenmiştir. Bina modeli çizimi için binanın gerçek boyutları ele alınmıştır. Model üzerindeki farklı etkileri gözlemlemek için 4 farklı yön seçilmiştir. Sırasıyla rüzgârın güneydoğu (durum 1) (ön kısım), kuzeybatı (durum 2) (arka kısım), kuzeydoğu (durum 3) (sağ kısım) ve güney bat1 (durum 4) (sol kısım) yönlerinden estiği durumlar için modelleme yapılmıştır.

Her bir durum için giriş rüzgâr hızı $40 \mathrm{~m} / \mathrm{s}$ ve giriş rüzgâr sıcaklığ $135^{\circ} \mathrm{C}$ olarak verilmiştir. Rüzgâr yönlerinin tespit edilmesi için Google haritalar uygulamas1 yardımıyla binanın uydu görüntüleri alınmıştır. Dicle üniversitesi 37,92 derece enlem ve 40,27 derece boylamda yer almaktadır (haritamap.com). Bina deniz seviyesinden 688 metre yükseklikte olduğu için sınır şartları atmosfer basıncında alınmıştır. Şekil 1.a'da binanın uydu görüntüsü ve rüzgâr yönleri verilmiştir. Binanın tüm yüzeylerine $25{ }^{\circ} \mathrm{C}$ sıcaklık tanımlanmıştır. Modelin diğer tüm kısımlarına açık sınır şartı verilmiştir. Modelin eleman sayısı 125630 olarak elde edilmiştir. Elde edilen bu ağ; binanın belirli bir koordinatı üzerindeki basınç değeri alınarak elde edilen izafi yaklaşım değerleri için ağdan bağımsız optimum ağ sayısıdır. Optimum ağ sayısının elde edilmesi için sonuçlar tablo 1'de verilmiştir. 
Tablo 1. Ağ bağımsılılık testi sonuçları

\begin{tabular}{|c|c|c|c|}
\hline & Ă̆ say1s1 & P (bar) & Yaklaşım(\%) \\
\hline Durum 1 & 116480 & 94115,80 & 4,12 \\
\hline Durum 2 & 125630 & 98160,12 & - \\
\hline Durum 3 & 145280 & 94676,04 & 3,68 \\
\hline
\end{tabular}

İzafi yaklaşım bir alt ağ sayısı 116480 eleman sayısı için \%4,12 olarak elde edilmiştir. Bir üst ağ sayıs1 145280 eleman sayısı için \%3,68 olarak elde edilmiştir. Şekil 1.b’de modelin ă̆ yapısı görülmektedir. Çalışmada üçgen ağ yerine düzgün dörtgen ağ yapısı kullanılmıştır. Skewnes değeri 0,18 olarak elde edilmiştir. Aşağıda viskoz, sıkıştırılamayan ve newtonien bir akışkanın üç boyutlu akışı için en genel halleri verilmiştir. (Launder., 1974, Menter., 1994)

Süreklilik denklemi:

$$
\frac{\partial u}{\partial x}+\frac{\partial v}{\partial y}+\frac{\partial w}{\partial z}=0
$$

x momentum denklemi:

$$
\begin{gathered}
\rho\left(\frac{\partial u}{\partial t}+u \frac{\partial u}{\partial x}+v \frac{\partial u}{\partial y}+w \frac{\partial u}{\partial z}\right)=F_{x}-\frac{\partial P}{\partial x}+ \\
\mu\left[\frac{\partial^{2} u}{\partial x^{2}}+\frac{\partial^{2} u}{\partial y^{2}}+\frac{\partial^{2} u}{\partial z^{2}}\right]
\end{gathered}
$$

y momentum denklemi:

$$
\begin{gathered}
\rho\left(\frac{\partial v}{\partial t}+u \frac{\partial v}{\partial x}+v \frac{\partial v}{\partial y}+w \frac{\partial v}{\partial z}\right)=F_{y}-\frac{\partial P}{\partial y}+ \\
\mu\left[\frac{\partial^{2} v}{\partial x^{2}}+\frac{\partial^{2} v}{\partial y^{2}}+\frac{\partial^{2} v}{\partial z^{2}}\right]
\end{gathered}
$$

z momentum denklemi:

$$
\begin{array}{r}
\rho\left(\frac{\partial w}{\partial t}+u \frac{\partial w}{\partial x}+v \frac{\partial w}{\partial y}+w \frac{\partial w}{\partial z}\right)=F_{z}-\frac{\partial P}{\partial z}+ \\
\mu\left[\frac{\partial^{2} w}{\partial x^{2}}+\frac{\partial^{2} w}{\partial y^{2}}+\frac{\partial^{2} w}{\partial z^{2}}\right]
\end{array}
$$
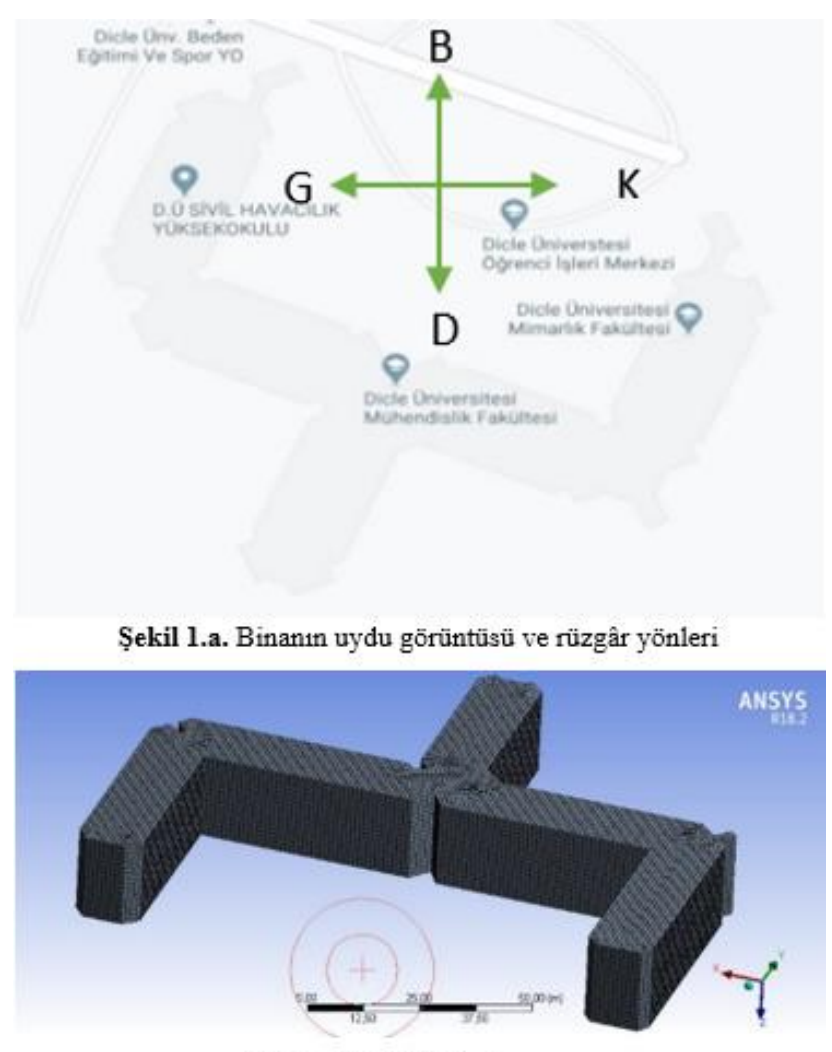

Șekil 1.b. Modelin ağ yappssı

Şekil 1. Binanın uydu görüntüsü, rüzgâr yönleri ve modelin ağ yapısı

Şekil 2.a'da model boyutları verilmiștir. Buradaki boyutlar binanın gerçek boyutlarında alınmıştır. Mesh sayısının ve çözüm zamanının artmaması için akış etkilerinin bina etrafinda gözlemlenebilir olduğu durum kadar hacim seçilmiştir.

Sınır şartları için örnek gösterim şekil 2.b' de durum 1 için verilmiştir. Sağ, sol, üst ve arka kenarlar açık sınır şartında seçilmiştir. Buralardaki basınç değeri 101325 $\mathrm{Pa}$, sıcaklık değeri $35{ }^{\circ} \mathrm{C}$ olarak verilmiștir. İç akışlarda genellikle k-w ya da nadiren Shear stress transport model (sst) tercih edilebilmektedir. $\mathrm{k}-\varepsilon$ model daha çok dış akışlarda sıklıkla kullanılan bir model olduğu için tercih edilmiştir. 


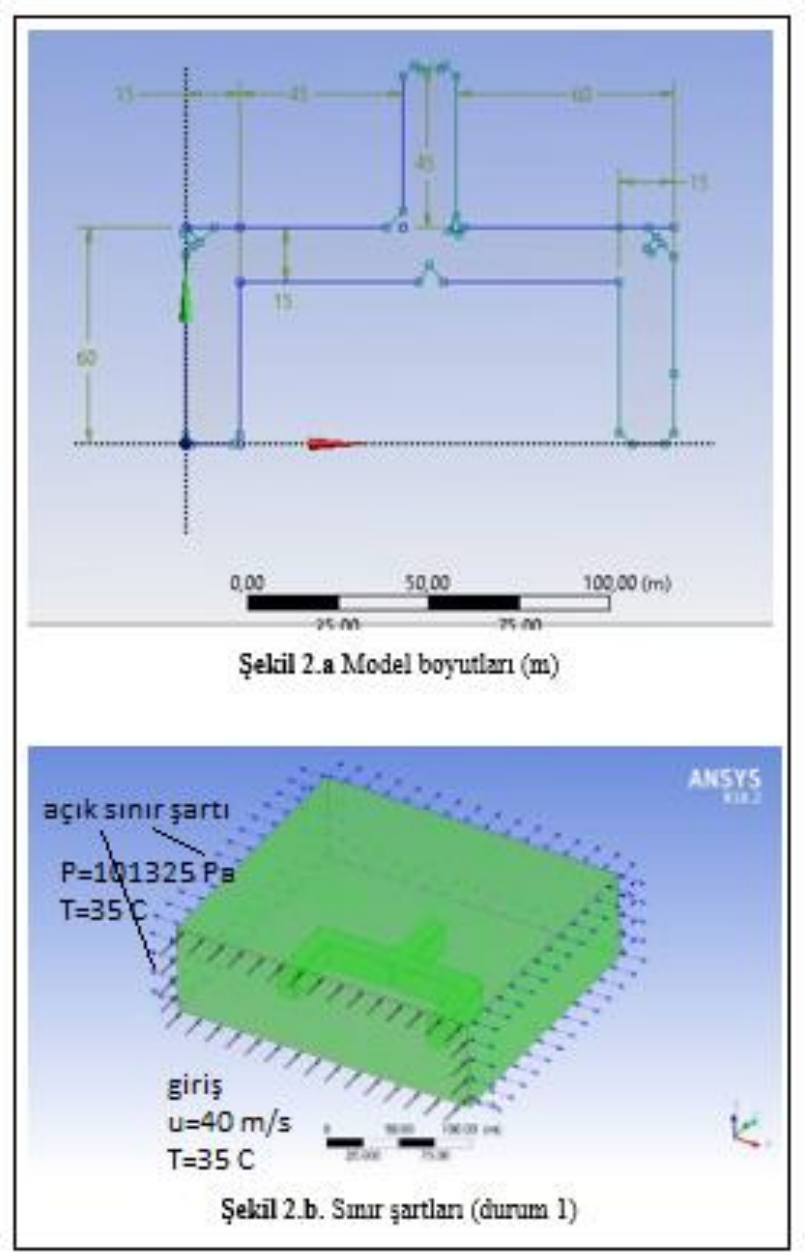

Şekil 2. Model boyutları ve sınır şartları

Şekil 3’te sırasıyla 4 farklı durum için rüzgâr yönü gösterimleri verilmiştir.

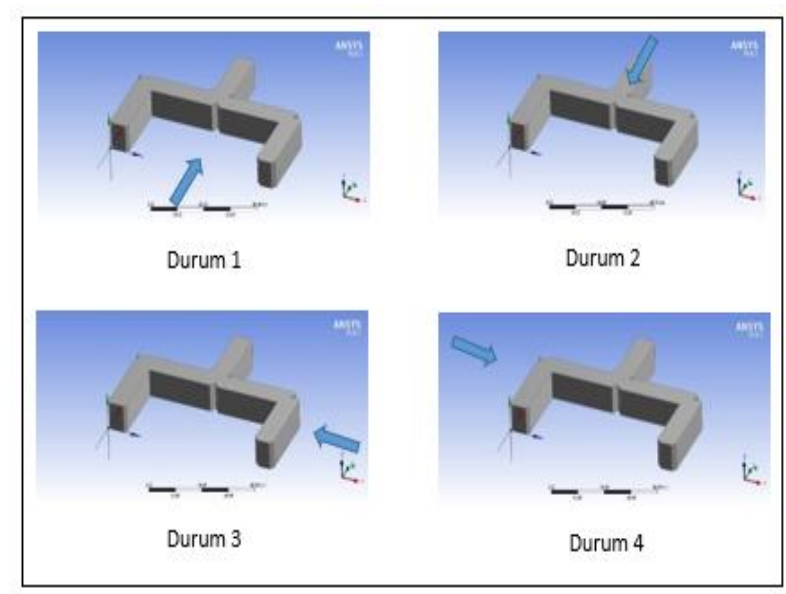

Şekil 3. Rüzgâr yönleri

\section{Bulgular ve Tartışma}

Şekil 4'a-d'de 4 farklı durum için hız konturleri görülmektedir. Binanın ön kısmından rüzgâr estiğinde (durum 1); binanın sağ ve sol uçlarının maksimum rüzgâr hızına maruz kaldığı görülmektedir. Özellikle bu kısımlarda yüksek seyreden rüzgâr hızları sürtünmeden dolayı gürültü ve titreşimi arttıracaktır. Akış ayrılması ve tekrar birleşimi sonucunda titreşim artacaktır. Rüzgâr arkadan estiğinde (durum 2) sadece binanın sağ kısmında maksimim rüzgâr değerleri izlenmiştir. Rüzgârın sağ (durum 3) ve soldan (durum 4) esmesi durumunda birbirine benzer sonuçlar elde edilmiştir. İlk 2 durumda ortalama rüzgâr hızları 47 $\mathrm{m} / \mathrm{s}$ değerlerinde iken durum 3 ve durum 4'de $\% 4,25$ artış göstererek $49 \mathrm{~m} / \mathrm{s}$ değerlerine kadar ulaşmıştır.

Akım çizgileri üzerinden girdaplar daha net görülebilir. Dolayısıyla; bina üzerindeki rüzgâr etkilerini akım çizgilerinden daha rahat görebiliriz. 4 farklı durum için akım çizgileri şekil 5'a-d'de verilmiştir. Dikkat edilirse ilk durumda girdaplar binanın arka kısmında oluşmuştur. İkinci durumda yani akışın binanın arkasından gönderildiği durumda ise binanın ön kısmında girdap oluşmamıştır. Rüzgâr binanın sağ kısmından gönderildiğinde binanın ön sağ uç kısmından akış ayrılmasının başladığı ve büyük bir girdap oluşturduğu görülmektedir. Benzer şekilde binanın sol kısmından rüzgâr gönderildiğinde binanın ön sol uç kısmından akış ayrılmasının ve büyük birkaç girdabın oluştuğu görülmektedir. Bu kısımlar gürültü ve titreşime daha çok maruz kalabilirler.
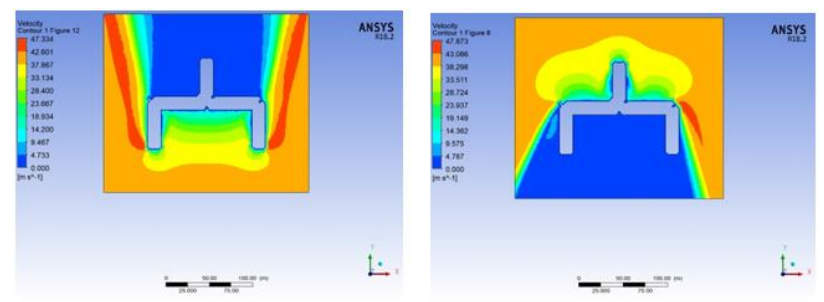

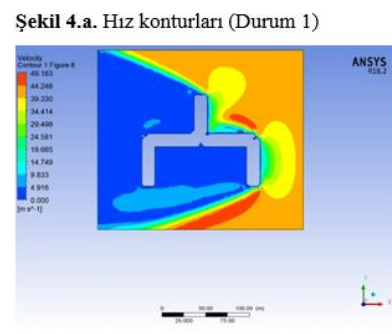

Şekil 4.c. Hız konturları (Durum 3)

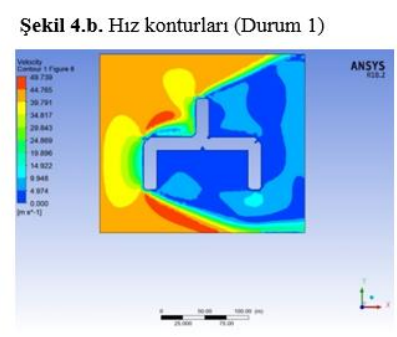

Şekil 4.d. Hız konturları (Durum 4) 
Şekil4. Farklı yönler için hız konturları
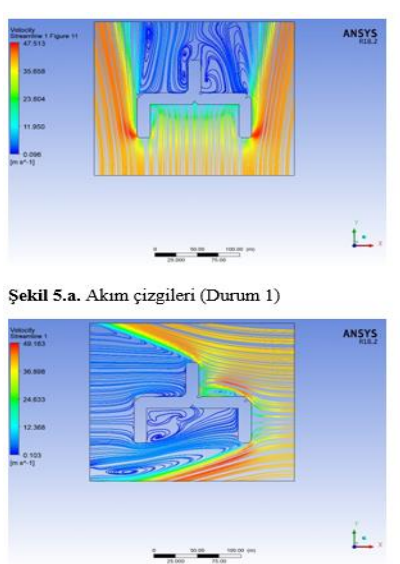

Şekil 5.a. Akım çizgileri (Durum 1)

Șekil 5.c. Akım çizgileri (Durum 3)

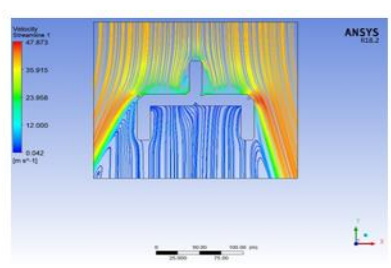

Şekil 5.b. Akım çizgileri (Durum 2)

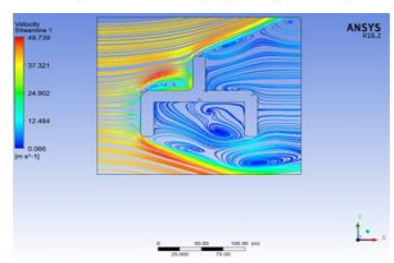

Şekil 5.d. Akım çizgileri (Durum 4)
Şekil 5. Farklı yönler için akım çizgileri

Binadan 10 metre yükseklikte binanın tam merkezinde bir çizgi boyunca rüzgârın binaya çarptıktan sonraki sıcaklık ve hızındaki değişimler 4 durum için incelenmiştir. Şekil 6'da binanın merkezinden 10 metre yükseklikten seçilen bina orta hat bölümü görülmektedir.

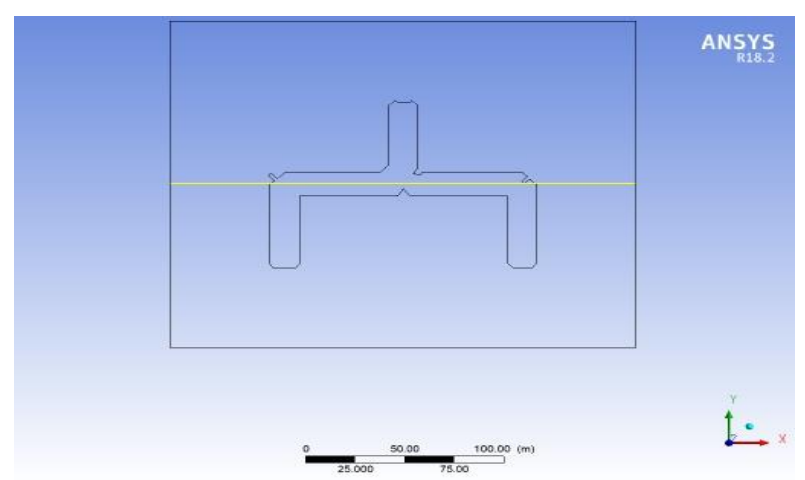

Şekil 6. Grafik için seçilen bina orta hat bölümü

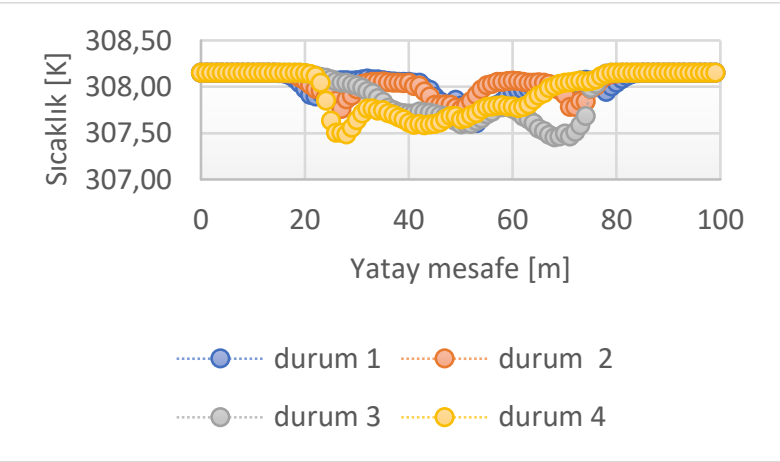

Şekil 7. Seçilen çizgi boyunca rüzgârın sıcaklık değerleri
Şekil 7'de seçilen bina orta hat bölümü boyunca rüzgârın sıcaklık değerleri görülmektedir. Rüzgâr sıcaklığı giriş sınır şartı için $35^{\circ} \mathrm{C}=308.15 \mathrm{~K}$, bina yüzey sicaklığ $125{ }^{\circ} \mathrm{C}=298.15 \mathrm{~K}$ olarak seçilmiştir. Grafik incelendiğinde; rüzgârın bina yüzeyine çarpması sonucu binanın orta bölgelerine doğru rüzgâr sıcaklığı yaklaşık 1 ila $1.5{ }^{\circ} \mathrm{C}$ civarı düşüş göstermiştir. Fakat rüzgâr sıcaklığı en fazla rüzgârın binanın sağ ve solundan esmesi durumunda gözlemlenmiştir. Bu durum yazın binanın soğutulması bakımından az da olsa bir avantajdır. Fakat rüzgârın artması aynı zamanda gürültü ve titreşimi de arttıracaktır. Binanın tam ortasındaki rüzgâr sıcaklıkları durum 1 için 34,86 K, durum 2 için 34,84 $\mathrm{K}$, durum 3 ve durum 4 için $34,64 \mathrm{~K}$ olarak elde edilmiştir. Binanın merkez noktasında durum 3 ve durum 4'deki rüzgâr sıcaklıkları durum 1 ve durum 2'ye göre $\% 0,63$ oranında azalmıştır.

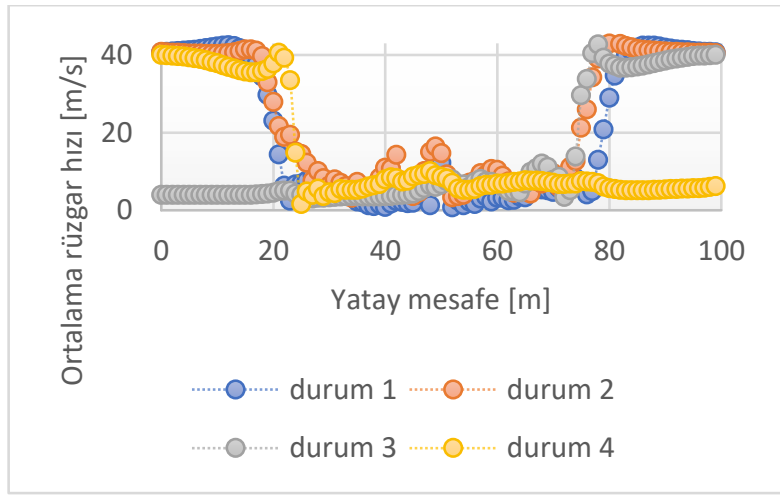

Şekil 8. Seçilen çizgi boyunca ortalama rüzgâr hızı değerleri

Şekil 8'de seçilen çizgi boyunca ortalama rüzgâr hızı değerleri görülmektedir. En yüksek ortalama rüzgâr hızı değerleri durum 2'de gözlemlenmiştir. Diğer 3 durumda birbirlerine benzer bir sonuç elde edilmiştir. Binanın orta bölgesindeki rüzgâr hızları yaklaşık 10 ila $15 \mathrm{~m} / \mathrm{s}$ aralığındadır. Binanın merkezinde durum 1 için rüzgâr hızı $0,8 \mathrm{~m} / \mathrm{s}$, durum 2 için $8,56 \mathrm{~m} / \mathrm{s}$, durum 3 için $1,86 \mathrm{~m} / \mathrm{s}$ durum 4 için 9,04 olarak elde edilmiştir. Bu bölgedeki rüzgâr hızı durum 1'e göre durum 2'de \%90,65 oranında artmıştır. Binanın sese ve titreşime maruz kalan kısmının binanın orta bölgeleri olduğu görülmüştür. Durma noktasının etkileri bu bölgelerde maksimum seviyededir. 


\section{Sonuç ve Öneriler}

Dicle Üniversitesi Mühendislik Fakültesi Binasının rüzgâra maruz kalması sonucu farklı rüzgâr yönlerinin bina üzerinde farklı etkilere sahip olduğu görülmüştür. Binanın orta hattı üzerinden alınan grafiklerde binanın rüzgâr sıcaklığının yaklaşık $1.5{ }^{\circ} \mathrm{C}$ civarı azaldığg 1 gözlemlenmiştir. Binanın merkez noktasındaki rüzgâr hizlarının durum 1'e göre durum 2'de \%90,65 oranında artış gösterdiği gözlemlenmiştir. Benzer şekilde binanın merkez noktasında durum 3 ve durum 4'deki rüzgâr sıcaklıkları durum 1 ve durum 2'ye göre $\% 0,63$ oranında azalmıştır. Binaya sağ ve soldan rüzgâr gönderildiğinde diğer iki duruma göre bina etrafinda daha büyük hava girdapları oluştuğu gözlenmiștir. Oluşan hava girdapları binanın bu kısımlarında gürültü ve titreşime yol açabilmektedir. $\mathrm{Bu}$ durumu önlemek için binanın bu yüzeylerine çeşitli ebatlarda hava perdeleri koyulabilir.

\section{ÇIKAR ÇATIŞMASI BEYANI}

Yazar/ Yazarlar bu makale ile ilgili herhangi bir çıkar çatışması bildirmemektedir.

\section{ARASTTIRMA VE YAYIN ETİĞİ BEYANI}

Yazar/Yazarlar bu çalışmanın araştırma ve yayın etiğine uygun olduğunu beyan eder.

\section{KAYNAKLAR}

Ali, K., Hua, G., Hoi, D. N., 2019. Effect of turbulence modeling schemes on wind-driven rain deposition on a mid-rise building: CFD modeling and validation, Journal of Wind Engineering \& Industrial Aerodynamics, 184, 362-377

ANSYS, (Academic Teaching Introductory) command References and gui.

Andrew, W. L., Wensu, C., Hong, H., Kaiming, B., 2020. Effect of inter-module connection stiffness on structural response of a modular steel building subjected to wind and earthquake load, Engineering Structures, 213, 110628

Bendine, K. , Alper, P., 2020. Numerical Modelling of Piezoelectric Based Energy Harvesting from The Bridge Structure, International Journal of Pure and Applied Sciences, 6(2):130-139

Cheng, Z., Senwen, Y., Chang, S., Liangzhu, W., Ted, S., 2020. Wind pressure coefficients for buildings with air curtains, Journal of Wind Engineering \& Industrial Aerodynamics, 205, 104265

Erdem, I., Volkan, T., 2017. Tunceli, Hakkâri ve Kars İllerinin Optimum Isı Yalıtım Kalınlığının
Hesaplanmas1, International Journal of Pure and Applied Sciences, 3(2): 50-57

Filmon, H., Arindam, G. C., Loannis, Z., 2017. Effect of wind-induced internal pressure on local frame forces of low-rise buildings, Engineering Structures, 143, 455-468

Gölbaşı D., Buyruk E., Şahin B., Karabulut K. 2017., Değişik Bina Modelleri İçin Akış Alanlarının Deneysel ve Sayısal Olarak İncelenmesi, Tesisat Mühendisliği, 162, 32-47

Gölbaşı D., Buyruk E., Şahin B., 2017 Karabulut K., Alnak D.E. "Experimental and Numerical Investigation of the Effect of Rooftop on the Flow Characteristic Between Two Buildings, 8th International Advanced Technologies, Symposium, Elazıg/Turkey, 8, 16051612

Gölbaşı D., Buyruk E., Şahin B. Karabulut K., Kılınç F. 2017., Bina Yüksekliği Değişiminin Akış Yapıları Üzerindeki Etkisinin Deneysel ve Sayısal Olarak İncelenmesi, ULİBTK17-21, Ulusal Is1 Bilimi ve Tekniği Kongresi, Çorum/Türkiye, 356-366

Gölbaşı D., Buyruk E., Karabulut K. 2018. Experimental and Numerical Research of the Flow Features Around the Building Pairs with Different Types, Cumhuriyet Science Journal, 39 (4), 1089-1106,

URL1 https://www.haritamap.com/yer/dicle-universitesisur

Hemant, M., Ashutosh, S., Ajay G., 2019. Numerical simulation of pedestrian level wind flow around buildings: Effect of corner modification and orientation, Journal of Building Engineering, 22, 314-326

Jae, H. K., Mohammadtaghi, M., Elaina, J. S., Arindam C., Thang, N. D., 2020. Observations and analysis of wind pressures on the floor underside of elevated buildings, Engineering Structures, 221, 11101

Jinsoo P., Xiang S., Jung, C., Gwang, H. R., 2017.Effect of wind and buoyancy interaction on single-sided ventilation in a building, Journal of Wind Engineering \& Industrial Aerodynamics, 171, 380389

Launder B.E. and Spalding D.B., 1974. The numerical computation of turbulent flows, Computer Methods In Applied Mechanics and Engineering, 3, $269-$ 289Leonidas, T., Marialena, N., 2019. The effect of building height and façade area ratio on pedestrian wind comfort of London, Journal of Wind Engineering \& Industrial Aerodynamics, 191, 63-75

Li B., Jiang, C., Wang, L., Cai, W., Liu, J. 2019. A parametric study of the effect of building layout on wind flow over an urban area, Building and Environment, 160, 106-160 
Menter F. R., 1994. Two-equation eddy-viscosity turbulence models for engineering applications, AIAA Journal, 32, 1598-1605.

Senwen, Y., Hatem, A., Cheng, Z., Dahai, Q., Liangzhu, W., Ted, S. 2019. Wind effects on air curtain performance at building entrances, Building and Environment, 151, 75-87

Timothy, W., Emil S., Gilliam, H., Jason, L., David, S. 1998. The use of aerodynamic databases for the efective estimation of wind effects in main windforce resisting systems: application to low buildings, Journal of Wind Engineeringand Industrial Aerodynamics, 77-78, 685-693

Xiao-Wei, Z., Hong-Nan, L., Chao, L., 2019. Damage probability analysis of a high-rise building against wind excitation with recorded field data and direction effect, Journal of Wind Engineering \& Industrial Aerodynamics, 184, 10-22 